\title{
Interruption of schistosomiasis transmission in mountainous and hilly regions with an integrated strategy: a longitudinal case study in Sichuan, China
}

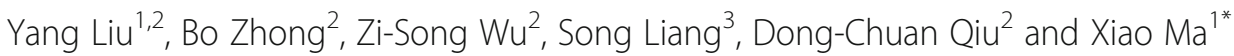

\begin{abstract}
Background: Schistosomiasis remains a major public health concern in China. Since 2004, an integrated strategy was developed to control the transmission of Schistosoma japonicum in China. However, the long-term effectiveness of this integrated strategy for the interruption of schistosomiasis transmission remains unknown in the mountainous and hilly regions of China until now. This longitudinal study aims to evaluate the effectiveness of the integrated strategy on transmission interruption of schistosomiasis in Sichuan Province from 2005 through 2014.

Methods: The data regarding replacement of bovines with machines, improved sanitation, access to clean water, construction of public toilets and household latrines, snail control, chemotherapy, and health education were captured from the annual report of the schistosomiasis control programmes in Sichuan Province from 2005 to 2014, and S. japonicum infection in humans, bovines and snails were estimated to evaluate the effectiveness of the integrated strategy.

Results: During the 10-year period from 2005 through 2014, a total of 536568 machines were used to replace bovines, and 3284333 household lavatories and 15523 public latrines were built. Tap water was supplied to 19116344 residents living in the endemic villages. A total of $230098 \mathrm{hm}^{2}$ snail habitats were given molluscicide treatment, and $357233 \mathrm{hm}^{2}$ snail habitats received environmental improvements. There were 7268138 humans and 840845 bovines given praziquantel chemotherapy. During the 10-year study period, information, education and communication (IEC) materials were provided to village officers, teachers and schoolchildren. The 10-year implementation of the integrated strategy resulted in a great reduction in S. japonicum infection in humans, bovines and snails. Since 2007, no acute infection was detected, and no schistosomiasis cases or infected bovines were identified since 2012. In addition, the snail habitats reduced by $62.39 \%$ in 2014 as compared to that in 2005, and no S. japonicum infection was identified in snails since 2007. By 2014, 88.9\% of the endemic counties achieved the transmission interruption of schistosomiasis and transmission control of schistosmiasis was achieved in the whole province in 2008.
\end{abstract}

Conclusion: The government-directed and multi-department integrated strategy is effective for interrupting the transmission of schistosomiasis in the mountainous and hilly regions of China.

Keywords: Schistosomiasis japonica, Transmission interruption, Integrated strategy, Longitudinal effectiveness, Source of infection, Sichuan Province, Mountainous and hilly region

\footnotetext{
* Correspondence: antiaids@163.com

'Department of Health Education, West China School of Public Health,

Sichuan University, No. 16 Renmin South Road, Chengdu 610041, Sichuan

Province, China

Full list of author information is available at the end of the article
} 


\section{Background}

Schistosomiasis ranks second only to malaria among the tropical parasitic diseases of its significant economic and public health consequences [1]. Worldwide, it is estimated that more than 200 million people are living with this infectious disease of poverty, with over 800 million at risk of infection [2]. In China, schistosomiasis remains a major public health concern nowadays [3].

Based on geographic, ecologic, and epidemiologic profiles, the schistosomiasis endemic foci are classified into three types in China, including marshland and lake regions, plain regions with waterway networks, and mountainous and hilly regions [4]. Unlike in marshland and lake regions and plain regions with waterway networks, the intermediate host Oncomelania hupensis snails are mainly distributed in ditches and rice paddy in mountainous and hilly regions of China [5]. Such a feature complicates the snail control efforts, either by using molluscicide treatment or environmental improvement [6].

From the initiation of the schistosomiasis control activities in 1950s until now, the schistosomiasis control strategy has shifted four times, with adaptation to local socio-economic and epidemiologic factors, including control of infected humans and livestock in 1950s, snail elimination-based integrated strategy from 1960 s to early 1980 s, chemotherapy-based integrated strategy from late 1980 s to 2003 , and the currently implemented integrated strategy with emphasis on controlling the sources of Schistosoma japonicum infection since 2004 [7].

Sichuan Province is located in southwestern China, and it is the most afflicted mountainous region by $S$. japonicum in the country, which has the largest snail habitats and most severe morbidity due to $S$. japonicum [8]. Historically, schistosomiasis was endemic in 63 counties of the province, with more than 10 million people at risk of infection [8]. The control efforts since 1950s, notably the implementation of the chemotherapybased integrated strategy since 1980s, had greatly reduced the prevalence and intensity of S. japonicum infection in Sichuan Province; however, the termination of the World Bank Loan Project for Chinese Schistosomiasis Control Program (WBLP), reform of specialized schistosomiasis institutions and reduced financial support to schistosomiasis control $[9,10]$, resulted in a reemergence of schistosomiasis in the province at early 2000s [11]. Since 2004, a new government-directed and multi-department integrated strategy was therefore proposed for elimination of schistosomiasis [12]. Here, we present the results from a 10-year longitudinal study pertaining to the effectiveness of this integrated strategy on elimination of schistosomiasis in Sichuan Province from 2005 through 2014.

\section{Methods}

\section{Data collection}

The data regarding replacement of bovines with machines, improved sanitation, access to clean water, construction of public toilets and household latrines, snail control, chemotherapy, and health education were captured from the annual report of the schistosomiasis control programmes in Sichuan Province from 2005 to 2014 [13-22].

\section{Snail survey}

At spring and autumn from 2005 to 2014, a snail survey was performed in historical snail habitats by means of the systematic sampling [13]. All snails captured in the field were transferred to laboratory, and identified for survival or death, and S. japonicum infection under a microscope [23]. The area of snail habitats, area with infected snails and snail infection rate were estimated.

\section{Detection of $S$. japonicum infection in humans and bovines}

During the non-transmission period from 2005 to 2014, all residents living in the villages endemic for S. japonicum were detected for specific IgG antibodies against $S$. japonicum with a diagnostic kit for Schistosoma antibody (ScAb) by colloidal gold method (Sichuan Maccura Biotechnology Co., Ltd.; Chengdu, China) [24-26]. Then, all sero-seropositive subjects were detected for S. japonicum infections with a miracidium hatching testing [27]. In addition, all bovines in the villages endemic for S. japonicum were detected for $S$. japonicum infection with a miracidium hatching test [28].

\section{Ethical statement}

This study was approved by the Ethical Review Committee of Sichuan Provincial Center for Disease Control and Prevention. All studies were performed in accordance with the international and national guidelines.

\section{Data management}

All data were processed with the software Microsoft Excel version 2007 (Microsoft Corporation; Redmond, WA, USA).

\section{Results}

Implementation of integrated control interventions

During the 10-year period from 2005 through 2014, a total of 536568 machines were used to replace bovines, and 3284333 household lavatories and 15523 public latrines were built, including three-cell septic tanks and marsh-gas pools. In addition, we supplied tap water to 19116344 residents living in the endemic villages (Table 1). A total of $230098 \mathrm{hm}^{2}$ snail habitats were given molluscicide treatment, and $357233 \mathrm{hm}^{2}$ snail habitats received environmental improvement. There 
Table 1 Improvement of sanitation and water resources in endemic areas from 2005 to 2014

\begin{tabular}{|c|c|c|c|c|c|c|c|c|c|}
\hline \multirow[t]{2}{*}{ Year } & \multicolumn{5}{|c|}{ Non-hazardous toilets } & \multicolumn{4}{|c|}{ Safe water resources } \\
\hline & $\begin{array}{l}\text { No. home } \\
\text { lavatories }\end{array}$ & $\begin{array}{l}\text { No. pubilc } \\
\text { latrines }\end{array}$ & $\begin{array}{l}\text { No. cumulative } \\
\text { household with } \\
\text { non-hazardous toilets }\end{array}$ & $\begin{array}{l}\text { No. household in } \\
\text { endemic areas }\end{array}$ & $\begin{array}{l}\text { Coverage } \\
\text { rate }(\%)\end{array}$ & $\begin{array}{l}\text { No. people with } \\
\text { safe water }\end{array}$ & $\begin{array}{l}\text { No. cumulative } \\
\text { people with safe } \\
\text { water }\end{array}$ & $\begin{array}{l}\text { No. people in } \\
\text { endemic areas }\end{array}$ & $\begin{array}{l}\text { Coverage } \\
\text { rate (\%) }\end{array}$ \\
\hline 2005 & 64056 & 52 & 293065 & 505284 & 58.00 & 1177177 & 5374517 & 9696043 & 55.43 \\
\hline 2006 & 161359 & 8453 & 353964 & 589940 & 60.00 & 1494462 & 5764536 & 9973246 & 57.80 \\
\hline 2007 & 216304 & 56 & 437850 & 695000 & 63.00 & 1446709 & 6477187 & 10363500 & 62.50 \\
\hline 2008 & 287599 & 1484 & 589201 & 906463 & 65.00 & 1681425 & 6959626 & 10434222 & 66.70 \\
\hline 2009 & 260626 & 212 & 658611 & 997895 & 66.00 & 2071942 & 7242199 & 10465606 & 69.20 \\
\hline 2010 & 647712 & 938 & 815726 & 1199597 & 68.00 & 2151305 & 7619722 & 10582948 & 72.00 \\
\hline 2011 & 444231 & 1120 & 915067 & 1307238 & 70.00 & 2006939 & 8380644 & 10675980 & 78.50 \\
\hline 2012 & 486441 & 1395 & 1039799 & 1444165 & 72.00 & 2586650 & 9200619 & 10837008 & 84.90 \\
\hline 2013 & 461253 & 1709 & 1028186 & 1370914 & 75.00 & 2201601 & 9912597 & 11001773 & 90.10 \\
\hline 2014 & 254752 & 104 & 936054 & 1215654 & 77.00 & 2298134 & 10909059 & 11246453 & 97.00 \\
\hline
\end{tabular}

were 7268138 humans and 840845 bovines given praziquantel chemotherapy. During the 10-year study period, information, education and communication (IEC) materials were provided to village officers, teachers and schoolchildren (Table 2).

\section{S. japonicum infection in human and bovines in Sichuan Province from 2005 to 2014}

During the 10-year longitudinal study period from 2005 to 2014, a total of 22539043 residents participated in the serological test, and 1780163 sero-positive individuals were subject to the miracidium hatching test. There were 7 023, 3 072, 1 215, 955, 1 080, 886, and 276 cases with schistosomiasis identified from 2005 to 2011, respectively; and no cases were detected since 2012 (Fig. 1). There was a tendency towards a decline in both the prevalence of $S$. japonicum human infection and the positive rate of serological test. There were 34 and 2 acute cases reported in 2005 and 2006, and no acute infections were detected since 2007.

From 2005 to 2011, a total of 2 767, 1 296, 232, 534, 90,66 , and 34 bovines were identified with $S$. japonicum infections, and no infection was found in bovines since 2012 (Fig. 2). A tendency towards a decrease was seen in the rate of $S$. japonicum infection in bovines across the study period.

\section{Dynamic shifts of snail status in Sichuan Province from 2005 to 2014}

During the 10-year longitudinal study period from 2005 to 2014, snail surveys were conducted at an area of 390 $157 \mathrm{hm}^{2}$, and $247494 \mathrm{hm}^{2}$ area was subject to snail control with molluscicide treatment and environmental improvement. During the 10-year period, the snail habitats fluctuated from 2058.5 to $6713.62 \mathrm{hm}^{2}$, and the snail habitats reduced by $62.39 \%$ in 2014 as compared to that

Table 2 Effectiveness of Health Education in Mountainous and hilly regions of Sichuan, China from 2005 to 2014

\begin{tabular}{|c|c|c|c|c|c|c|c|c|c|c|c|}
\hline \multirow[t]{3}{*}{ Year } & \multirow{3}{*}{$\begin{array}{l}\text { Health education } \\
\text { materials }\end{array}$} & \multirow{3}{*}{$\begin{array}{l}\text { Medium } \\
\text { publicity }\end{array}$} & \multirow{3}{*}{$\begin{array}{l}\text { Training for } \\
\text { village officers }\end{array}$} & \multirow{3}{*}{$\begin{array}{l}\text { Training for } \\
\text { teachers }\end{array}$} & \multirow{3}{*}{$\begin{array}{l}\text { Protection } \\
\text { products }\end{array}$} & \multirow{3}{*}{ Posters } & \multirow[t]{3}{*}{ Slogan } & \multicolumn{4}{|c|}{ Prevention and control knowledges } \\
\hline & & & & & & & & \multicolumn{2}{|c|}{ Awareness rate (\%) } & \multicolumn{2}{|c|}{ Correct behavior formation rate (\%) } \\
\hline & & & & & & & & Children & Women & Children & Women \\
\hline 2005 & 1743865 & 2483 & 466 & 2688 & 11063 & 6334 & 4151 & & & & \\
\hline 2006 & 1746208 & 2520 & 583 & 2614 & 9087 & 2939 & 4206 & & & & \\
\hline 2007 & 1668622 & 2559 & 506 & 2685 & 5407 & 2433 & 10175 & & & & \\
\hline 2008 & 2355221 & 2755 & 490 & 2784 & 6077 & 2800 & 7973 & 91.5 & 90.50 & 83.1 & 80.5 \\
\hline 2009 & 2591166 & 2576 & 518 & 2836 & 7018 & 2283 & 9872 & & & & \\
\hline 2010 & 1759749 & 2786 & 507 & 2723 & 18036 & 2700 & 10179 & & & & \\
\hline 2011 & 3660317 & 2589 & 5544 & 2793 & 19455 & 2617 & 8837 & & & & \\
\hline 2012 & 4074518 & 2649 & 6545 & 2752 & 21158 & 2706 & 6890 & & & & \\
\hline 2013 & 4627189 & 2629 & 6562 & 2726 & 24618 & 4597 & 8283 & & & & \\
\hline 2014 & 4417960 & 2614 & 5524 & 2765 & 22948 & 4089 & 7910 & 96.85 & 95.01 & 96.31 & 94.09 \\
\hline
\end{tabular}




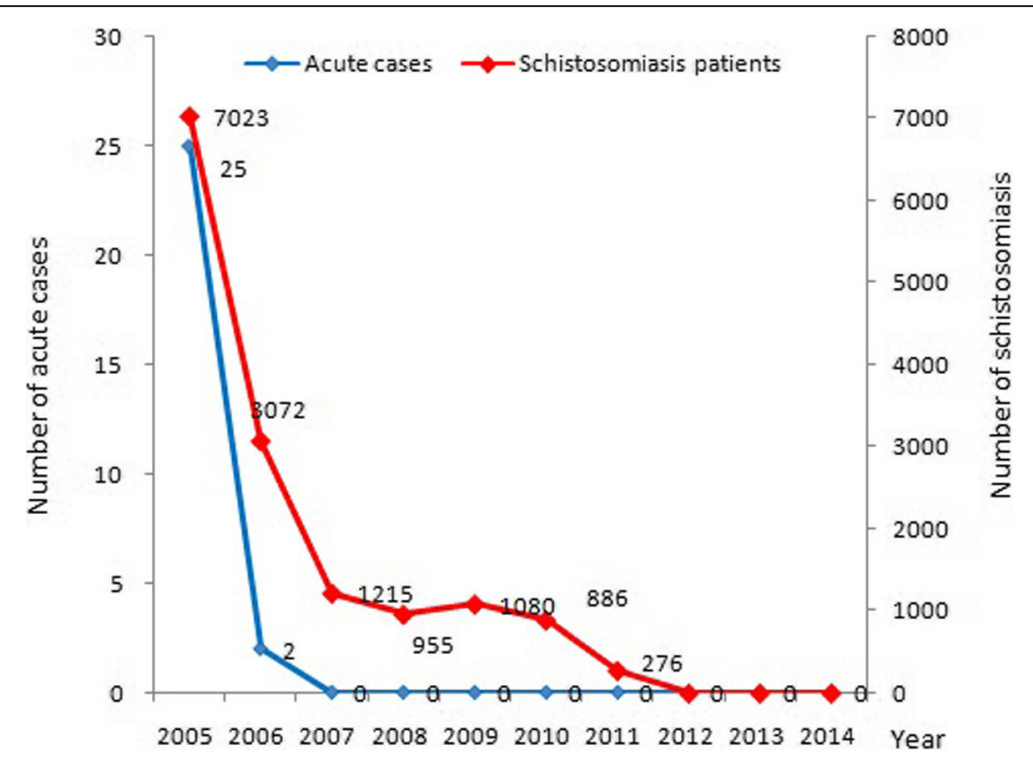

Fig. 1 Number of schistosomiasis cases and acute cases in Sichuan Province from 2005 to 2014

in 2005, and no S. japonicum infection was identified in snails since 2007 (Fig. 3).

\section{Overall status of schistosomiasis control in Sichuan Province from 2005 to 2014}

The 10-year implementation of the integrated strategy from 2005 to 2014 greatly reduced the prevalence of $S$. japonicum in humans, bovines and snails, as well as the acute schistosomiasis cases. By 2014, there were 56 out of the 63 endemic counties achieving the transmission interruption of schistosomiasis and 7 counties achieving transmission control (Table 3; Figs. 4 and 5) [29]. In addition, transmission control of schistosmiasis was achieved in the whole province in 2008.

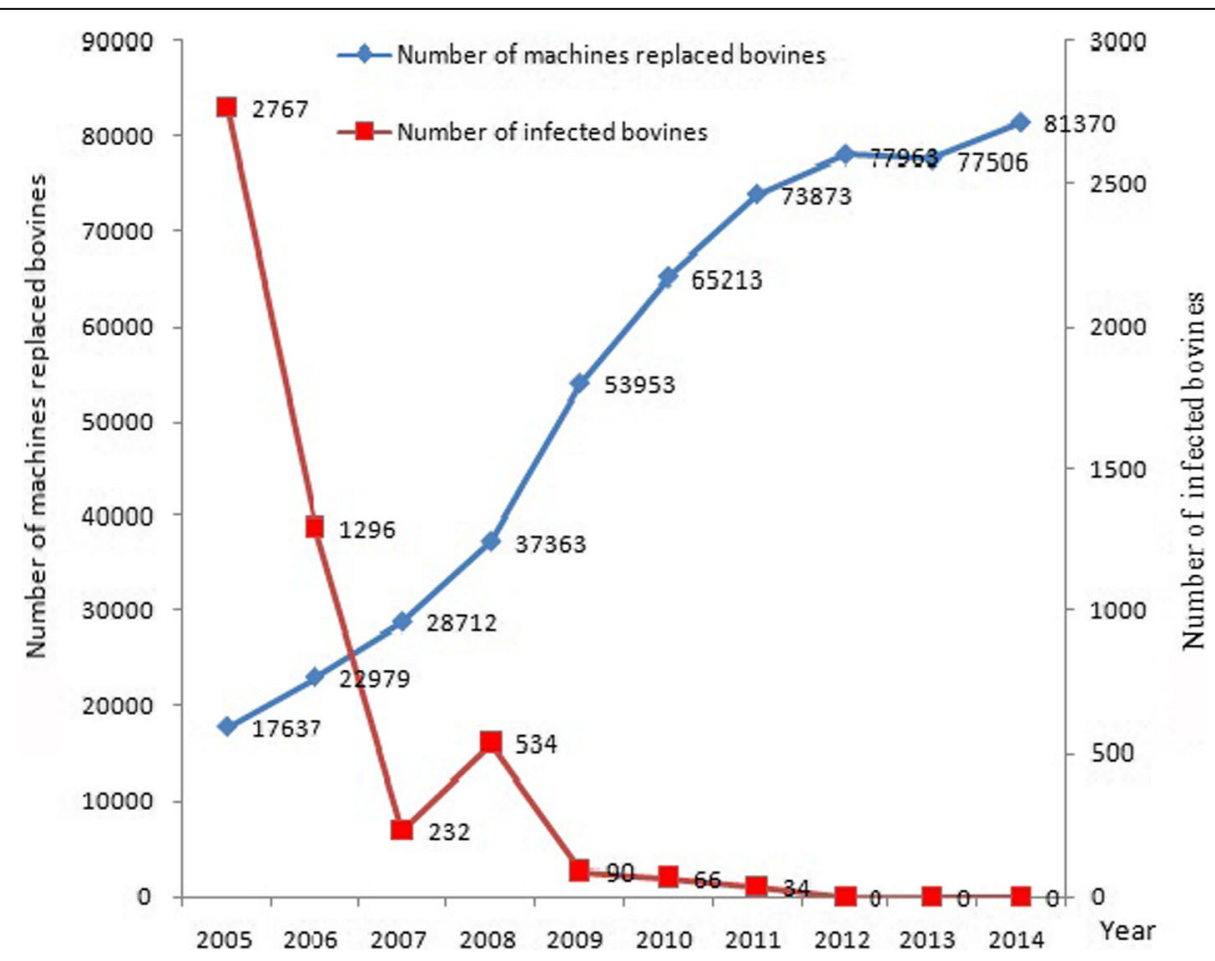

Fig. 2 Number of bovines replaced by machines and S. japonicum-infected bovines in Sichuan Province from 2005 to 2014 


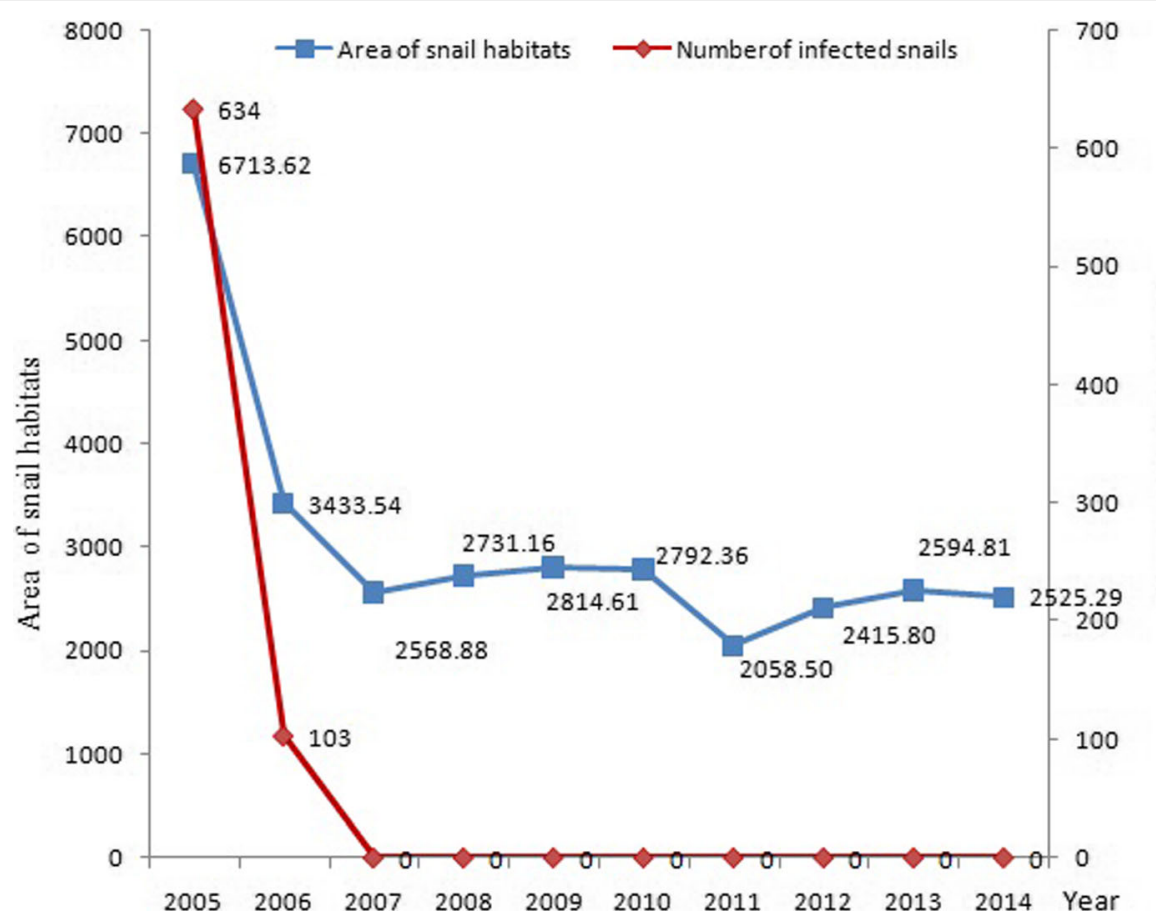

Fig. 3 Annual area of snail habitats and annual number of S. japonicum-infected snails in Sichuan Province from 2005 to 2014

\section{Discussion}

Over the past six decades, the national schistosomiasis control strategy of China has shifted three times, according to the socio-economic status and epidemiological profiles [30, 31]. The snail control-based integrated control strategy, which was employed from early 1950s to early 1980s, had greatly shrink snail habitats; however, snail cannot be eliminated completely, resulting in

Table 3 Annual number of counties achieving transmission interruption and control in Sichuan from 2005 to 2014

\begin{tabular}{llll}
\hline Year & No. counties & $\begin{array}{l}\text { No. transmission } \\
\text { interruption }\end{array}$ & $\begin{array}{l}\text { No. transmssion } \\
\text { control }\end{array}$ \\
\hline 2005 & 62 & 28 & 25 \\
2006 & 62 & 28 & 30 \\
2007 & 62 & 28 & 34 \\
$2008^{\text {a }}$ & 63 & 27 & 36 \\
2009 & 63 & 27 & 36 \\
2010 & 63 & 31 & 32 \\
2011 & 63 & 34 & 29 \\
2012 & 63 & 41 & 22 \\
2013 & 63 & 48 & 15 \\
2014 & 63 & 56 & 7 \\
\hline
\end{tabular}

${ }^{a}$ The total number of endemic counties increased to 63 since 2008, 20 endemic villages were divided to Beichuan Qiang Minority Autonomous County which was not a schistosomiasis endemic area frequent re-emergence of schistosomiasis. With the introduction of praziquantel, the national schistosomiasis control strategy of China shifted from transmission control to morbidity control from mid-1980s until 2003. Such a strategy had greatly reduced the prevalence and intensity of S. japonicum infection; however, praziquantel cannot prevent re-infection, and humans and livestock may get infections following contact with $S$. japonicum-infested water even if being given chemotherapy with praziquantel. In 2004, a new integrated strategy was developed to control the transmission of S. japonicum, through chemotherapy for humans and livestock, snail control, health education, improved sanitation, access to safe water, replacement of bovines with machines, raising bovines in fences [32].

The integrated strategy with emphasis on infectious source control was proposed based on the recognition that bovine is the predominant source of $S$. japonicum infection in the marshland and lake regions [33,34], and this strategy has been widely proved to be effective for the elimination of schistosomiasis in the marshland and lake regions of China [35-42]. In the survey in 1980s showed that humans were responsible for up to $88 \%$ of the schistosome egg excretion to the environment with cattle being responsible for most of the remainder. Dogs and voles have been found to be infected, but contribute little to the transmission cycle due to their low infection rate and small amount of feces in mountainous and hilly 


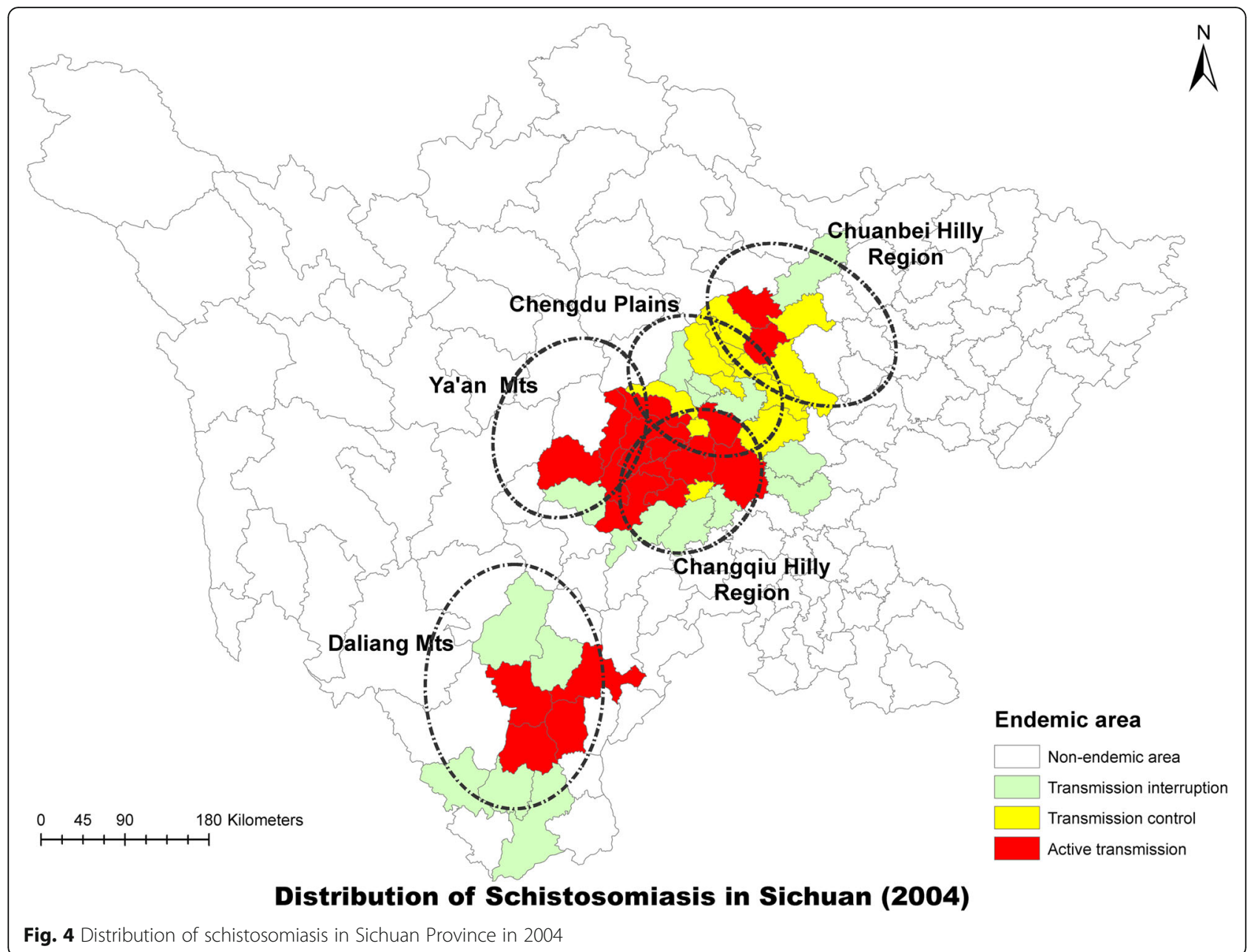

regions [43]. However, there is a question about the effectiveness of this strategy for schistosomiasis elimination in the mountainous and hilly regions [44]. Previous studies have demonstrated the short-term effectiveness of the integrated strategy to control the transmission of $S$. japonicum in the mountainous areas of China [45-47]. However, the long-term effectiveness of the new integrated strategy for schistosomiasis elimination remains unknown in the mountainous and hilly regions of China until now.

Since 2005, a 10-year longitudinal study was designed with aims to evaluate the long-term effectiveness of a new government-directed and multi-department integrated strategy on elimination of schistosomiasis in $\mathrm{Si}$ chuan Province from 2005 through 2014. To block the transmission cycle of the parasite, supply of safe tap water and the construction of lavatories and latrines were performed, and the coverage of non-hazardous toilets and safe water increased from $58 \%$ and 55 to 77 and $97 \%$ in the endemic villages, respectively. The 10 year implementation of the integrated strategy resulted in a great reduction in the $S$. japonicum infection in humans, bovines and snails. Since 2007, no acute infection was detected, and no schistosomiasis cases or infected bovines were identified since 2012. In addition, the snail habitats reduced by $62.39 \%$ in 2014 as compared to that in 2005, and no S. japonicum infection in snails was detected since 2007. By 2014, $88.9 \%$ of the endemic counties achieved the transmission interruption of schistosomiasis and transmission control of schistosomiasis was achieved in the whole province in 2008. Our data demonstrate that the integrated strategy is effective for the elimination of schistosomiasis in the mountainous and hilly regions of China.

In 2015, transmission interruption of schistosomiasis was achieved in Sichuan Province [48], and the agenda for schistosomiasis elimination was set by 2023 [49]. There are several challenges for achieving this great goal. (1) Governmental leadership and financial supports. Political commitment and financial support are critically important to the effective schistosomiasis control [22]. Efforts should be made 


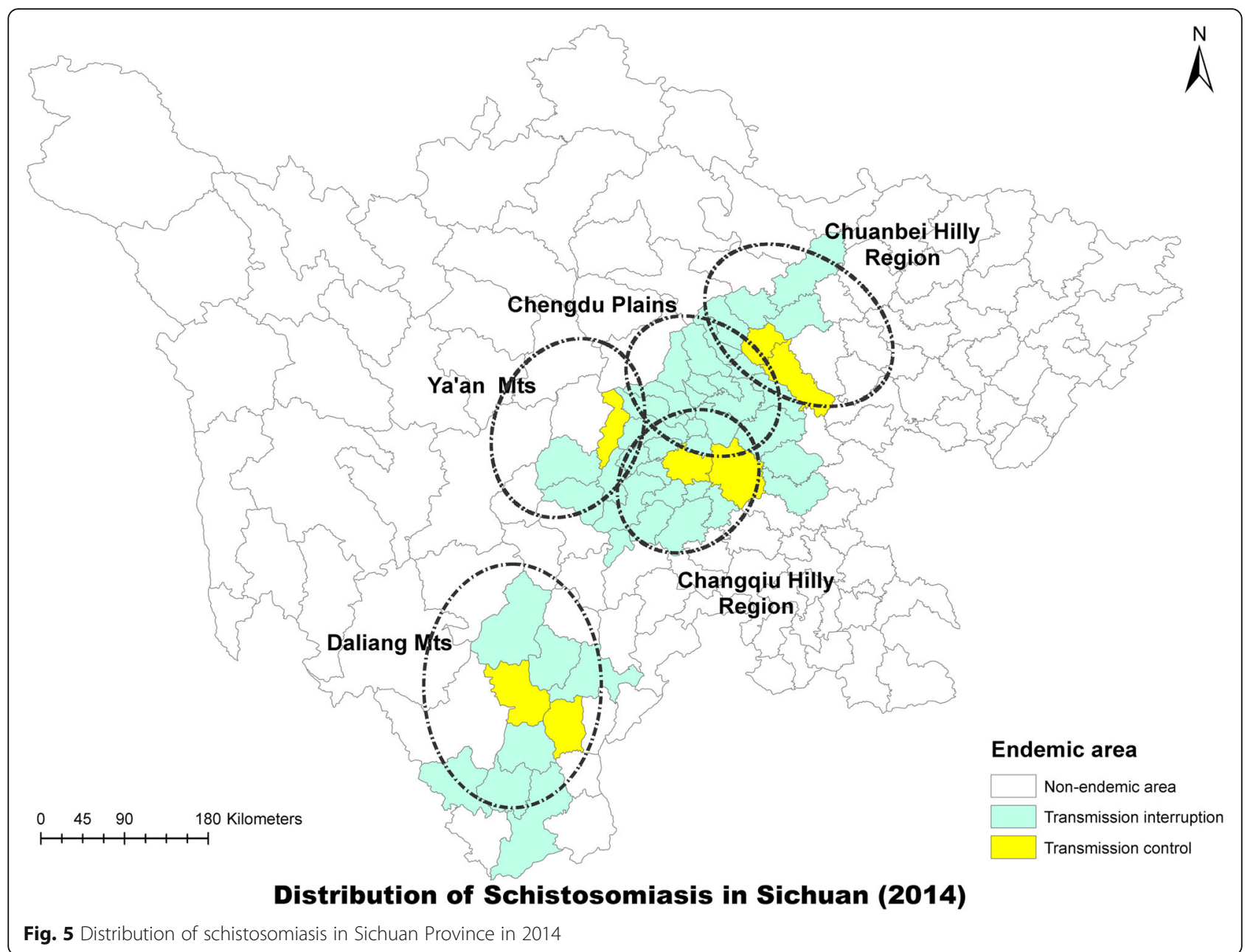

to enhance the leadership and financial supports from various levels of governments. However, the government leadership and financial support may reduce after transmission control and interruption of schistosomiasis is achieved, which may affect the progress towards the elimination of schistosomiasis. (2) The transmission of schistosomiasis is complex, involving social, natural, economic factors. O. hupensis snails are usually distributed in complicated mountainous settings, which are difficult for elimination, and bovines are hard to be removed since they have been integrated into local agricultural production and transportation. In addition, numerous wild reservoir hosts complicate the control efforts. (3) Population and bovine migration. There are a large number of humans and livestock migrating from and immigrating into Sichuan Province, which greatly challenges the progress towards the elimination of schistosomiasis. (4) Need of a sensitive and effective surveillance-response system. Currently, schistosomiasis has been reduced to a low-intensity of infection in Sichuan Province, and routine tools are difficult for the identification of human infections. A sensitive and effective surveillance-response system is therefore urgently required for active case finding and rapid response [50-52].

\section{Conclusions}

The results of the present study demonstrate that the government-directed and multi-department integrated strategy is effective for the interruption of schistosomiasis transmission in the mountainous and hilly regions of China.

\section{Abbreviations}

WBLP: World Bank Loan Project for Chinese Schistosomiasis Control Program; IEC: Information, education and communication

\section{Acknowledgements}

We would like to thank the staff from the Department of Schistosomiasis Control in the Institute of Parasitic Diseases, Sichuan Provincial Center for Disease Control and Prevention for their kind participation in the field work. 


\section{Funding}

This study was supported by the grant from the China UK Global Health Support Programme (grant no. GHSPOP101).

\section{Availability of data and materials}

All data described in the study can be provided by contact with the corresponding author.

\section{Authors' contributions}

$Y L$ and $X M$ conceived and designed the study. YL, BZ, ZSW and DCQ performed the field work. YL collected and analyzed the data. YL prepared the first version of the manuscript. SL provided valuable comments on the revision of the manuscript. XM revised and finalized the manuscript. All authors read and approved the final version of the manuscript.

\section{Competing interests}

The authors declare no competing interests.

\section{Consent for publication}

All authors consent for publication of this study.

\section{Ethics approval and consent to participate}

This study was approved by the Ethical Review Committee of Sichuan Provincial Center for Disease Control and Prevention. All studies were performed in accordance with the international and national guidelines.

\section{Author details}

'Department of Health Education, West China School of Public Health, Sichuan University, No. 16 Renmin South Road, Chengdu 610041, Sichuan Province, China. ${ }^{2}$ Sichuan Provincial Center for Disease Control and Prevention, No. 6 Zhongxue Road, Chengdu 610041, Sichuan Province, China. ${ }^{3}$ Department of Environmental \& Global Health, College of Public Health and Health Professions, University of Florida, Gainesville, FL, USA.

\section{Received: 15 February 2017 Accepted: 19 March 2017}

\section{Published online: 07 April 2017}

\section{References}

1. Colley DG, Bustinduy AL, Secor WE, King CH. Human schistosomiasis. Lancet. 2014;383:2253-64.

2. Gray DJ, McManus DP, Li Y, Williams GM, Bergquist R, Ross AG. Schistosomiasis elimination: lessons from the past guide the future. Lancet Infect Dis. 2010;10:733-6.

3. Chen MG. Assessment of morbidity due to Schistosoma japonicum infection in China. Infect Dis Poverty. 2014;3:6.

4. Zhou YB, Liang S, Chen Y, Jiang QW. The Three Gorges Dam: Does it accelerate or delay the progress towards eliminating transmission of schistosomiasis in China? Infect Dis Poverty. 2016:5:63.

5. Liu Y, Zhou YB, Li RZ, Wan JJ, Yang Y, Qiu DC, Zhong B. Epidemiological features and effectiveness of schistosomiasis control Programme in mountainous and hilly region of the People's republic of china. Adv Parasitol. 2016;92:73-95.

6. Zhou YB, Chen Y, Liang S, Song XX, Chen GX, He Z, Cai B, Yihuo WL, He ZG, Jiang QW. Multi-host model and threshold of intermediate host Oncomelania snail density for eliminating schistosomiasis transmission in China. Sci Rep. 2016;6:31089.

7. Xu JF, Lv S, Wang QY, Qian MB, Liu Q, Bergquist R, Zhou XN. Schistosomiasis japonica: modelling as a tool to explore transmission patterns. Acta Trop. 2015:141:213-22.

8. Wan JJ, Xu L, Wu ZS, Xu J, Chen L, Liu Y, Zhong B. Schistosomiasis control progress and endemic situation in Sichuan Province. Chin J Schisto Control. 2016;28:713-6.

9. Zhou YB, Liang S, Jiang QW. Factors impacting on progress towards elimination of transmission of schistosomiasis japonica in China. Parasit Vectors. 2012;5:275.

10. Spear RC, Seto EY, Carlton EJ, Liang S, Remais JV, Zhong B, Qiu DC. The challenge of effective surveillance in moving from low transmission to elimination of schistosomiasis in China. Int J Parasitol. 2011:41:1243-47.

11. Liang S, Yang C, Zhong B, Qiu D. Re-emerging schistosomiasis in hilly and mountainous areas of Sichuan, China. Bull World Health Organ. 2006;84: $139-44$
12. Wang LD, Chen HG, Guo JG, Zeng XJ, Hong XL, Xiong JJ, Wu XH, Wang XH, Wang LY, Xia G, Hao Y, Chin DP, Zhou XN. A strategy to control transmission of Schistosoma japonicum in China. N Engl J Med. 2009;360:121-8.

13. Hao Y, Wu XH, Xia G, Zheng H, Guo JG, Wang LY, Zhou XN. Schistosomiasis situation in People's Republic of China in 2005. Chin J Schisto Control. 2006; 18:321-4.

14. Hao Y, Wu XH, Zheng H, Wang LY, Guo JG, Xia G, Chen Z, Zhou XN. Schistosomiasis situation in People's Republic of China in 2006. Chin J Schisto Contro. 2007;19:401-4.

15. Hao Y, Wu XH, Zheng H, Wang LY, Guo JG, Xia G, Chen Z, Zhou XN. Schistosomiasis situation in People's Republic of China in 2007. Chin J Schisto Control. 2008;20:401-4.

16. Hao Y, Zheng H, Zhu R, Guo JG, Wu XH, Wang LY, Chen Z, Zhou XN. Schistosomiasis situation in People's Republic of China in 2008. Chin J Schisto Control. 2009:21:451-6.

17. Hao Y, Zheng H, Zhu R, Guo JG, Wang LY, Chen Z, Zhou XN. Schistosomiasis situation in People's Republic of China in 2009. Chin J Schisto Control. 2010;22:521-7.

18. Lei ZL, Zheng H, Zhang LJ, Zhu R, Guo JG, Li SZ, Wang LY, Chen Z, Zhou XN. Schistosomiasis status in People's Republic of China in 2010. Chin J Schisto Control. 2011:23:599-604.

19. Zheng H, Zhang LJ, Zhu R, Xu J, Li SZ, Guo JG, Xiao N, Zhou XN. Schistosomiasis situation in People's Republic of China in 2011. Chin J Schisto Control. 2012;24:621-6.

20. Li SZ, Zheng H, Gao J, Zhang LJ, Zhu R, Xu J, Guo JG, Xiao N, Zhou XN. Endemic status of schistosomiasis in People's Republic of China in 2012 Chin J Schisto Control. 2013;25:557-63.

21. Lei ZL, Zheng H, Zhang LJ, Zhu R, Xu ZM, Xu J, Fu Q, Wang Q, Li SZ, Zhou $X N$. Endemic status of schistosomiasis in People's Republic of China in 2013. Chin J Schisto Control. 2014;26:591-6.

22. Lei ZL, Zhang LJ, Xu ZM, Dang H, Xu J, Lv S, Cao CL, Li SZ, Zhou XN. Endemic status of schistosomiasis in People's Republic of China in 2014 Chin J Schisto Control. 2015;27:563-9.

23. Li ZJ, Ge J, Dai JR, Wen LY, Lin DD, Madsen H, Zhou XN, Lv S. Biology and control of snail intermediate host of Schistosoma japonicum in the People's Republic of China. Adv Parasitol. 2016:92:197-236.

24. Zhang JF, Xu J, Bergquist R, Yu LL, Yan XL, Zhu HQ, Wen LY. Development and application of diagnostics in the national schistosomiasis control Programme in the People's Republic of China. Adv Parasitol. 2016;92:409-34.

25. Zhou XN, XU J, Chen HG, Wang TP, Huang XB, Lin DD, Wang QZ, Tang L, Guo JG, Wu XH, Feng T, Chen JX, Guo J, Chen SH, Li H, Wu ZD, Peeling RW. Tools to support policy decisions related to treatment strategies and surveillance of Schistosomiasis japonica towards elimination. PLoS Negl Trop Dis. 2011:5:e1408.

26. Xu J, Peeling RW, Chen JX, Wu XH, Wu ZD, Wang SP, Feng T, Chen SH, Li H, Guo JG, Zhou XN. Evaluation of immunoassays for the diagnosis of Schistosoma japonicum infection using archived sera. PLoS Negl Trop Dis. 2011:5:e949.

27. Zhu HQ, Xu J, Zhu R, Cao CL, Bao ZP, Yu Q, Zhang LJ, Xu XL, Feng Z, Guo $J G$. Comparison of the miracidium hatching test and modified Kato-Katz method for detecting Schistosoma japonicum in low prevalence areas of China. Southeast Asian J Trop Med Public Health. 2014:45:20-5.

28. Li H, Dong GD, Liu JM, Gao JX, Shi YJ, Zhang YG, Jin YM, Lu K, Cheng GF, Lin JJ. Elimination of schistosomiasis japonica from formerly endemic areas in mountainous regions of southern China using a praziquantel regimen. Vet Parasitol. 2015;208:254-8.

29. Zou L, Ruan S. Schistosomiasis transmission and control in China. Acta Trop. 2015;143:51-7.

30. Xu J, Steinman P, Maybe D, Zhou XN, Lv S, Li SZ, Peeling R. Evolution of the national schistosomiasis control programmes in the People's Republic of China. Adv Parasitol. 2016:92:1-38.

31. Collins C, Xu J, Tang S. Schistosomiasis control and the health system in P.R China. Infect Dis Poverty. 2012;1:8.

32. Wang W, Dai JR, Liang YS. Apropos: factors impacting on progress towards elimination of transmission of schistosomiasis japonica in China. Parasit Vectors. 2014;7:408.

33. Gray DJ, Williams GM, Li Y, McManus DP. Transmission dynamics of Schistosoma japonicum in the lakes and marshlands of China. PLoS One. 2008;3:e4058.

34. Yang GJ, Utzinger J, Zhou XN. Interplay between environment, agriculture and infectious diseases of poverty: case studies in China. Acta Trop. 2015: 141:399-406. 
35. Wang $X$, Wang $W$, Wang P. Long-term effectiveness of the integrated schistosomiasis control strategy with emphasis on infectious source control in China: a 10-year evaluation from 2005 to 2014. Parasitol Res. 2017;116: $521-8$.

36. Liu R, Dong HF, Jiang MS. The new national integrated strategy emphasizing infection sources control for schistosomiasis control in China has made remarkable achievements. Parasitol Res. 2013;112:1483-91.

37. Hong XC, Xu XJ, Chen X, Li YS, Yu CH, Yuan Y, Chen YY, Li RD, Qiu J, Liu ZC, Yi P, Ren GH, He HB. Assessing the effect of an integrated control strategy for schistosomiasis japonica emphasizing bovines in a marshland area of Hubei Province, China: a cluster randomized trial. PLoS Negl Trop Dis. 2013; 7:e2122.

38. Chen YY, Liu JB, Huang XB, Cai SX, Su ZM, Zhong R, Zou L, Miao XP. New integrated strategy emphasizing infection source control to curb Schistosomiasis japonica in a marshland area of Hubei Province, China: findings from an eight-year longitudinal survey. PLoS One. 2014;9:e89779.

39. Chen Z, Rao XL, Li YF, Gu XN, Xu MX, Lin DD. Effect of schistosomiasis control strategy based on infection source control of Poyang Lake region in Yongxiu County promotion zone. Chin J Schisto Control. 2015;27:579-82 (in Chinese).

40. Zeng XJ, Chen HG, Hong XL, Hu ZH, Jiang WS, Hu SZ, Fan YL, Ge J. Evaluation on medium-term effect of schistosomiasis comprehensive control strategy based on infectious source control in Poyang Lake area. Chin J Schisto Control. 2012;24:382-6 (in Chinese).

41. Wang LD, Guo JG, Wu XH, Chen HG, Wang TP, Zhu SP, Zhang ZH, Steinmann $P$, Yang GJ, Wang SP, Wu ZD, Wang LY, Hao Y, Bergquist R, Utzinger J, Zhou XN. China's new strategy to block Schistosoma japonicum transmission: experiences and impact beyond schistosomiasis. Trop Med Int Health. 2009;14:1475-83.

42. Xu J, Xu JF, Li SZ, Zhang LJ, Wang Q, Zhu HH, Zhou XN. Integrated control programmes for schistosomiasis and other helminth infections in P.R. China. Acta Trop. 2015;141:332-41.

43. Xu FS, Gu XG, Zhao WX, Li XY, Yin HZ, Zhao LG, Zhou XF, Li XJ. Effect of Schistosomiasis Control and prevention in Chuanxing County, Xichang, 1987-1995. J Pract Parasit Dis. 1995;3:129-30.

44. Seto EY, Remais JV, Carlton EJ, Wang S, Liang S, Brindley PJ, Qiu D, Spear RC, Wang LD, Wang TP, Chen HG, Dong XQ, Wang LY, Hao Y, Bergquist R, Zhou $\mathrm{XN}$. Toward sustainable and comprehensive control of schistosomiasis in China: lessons from Sichuan. PLoS Negl Trop Dis. 2011;5:e1372.

45. Yang K, Li HJ, Yang WC, Shi XW, Qi YL. Effect of comprehensive schistosomiasis control measures with emphasis on infectious source control in dam areas of mountainous region, Yunnan Province. Chin $J$ Schisto Control. 2009;21:272-75 (in Chinese).

46. Chen SR, Li BG, Luo JJ, Li WB, Mu LX, Tian SH, Li P, Liu YH, Yang H, Wang SW, Chen F, Luo BR, Li KR, Duan YC. Effect of comprehensive schistosomiasis control measures based on infection source control in mountainous areas of Yunnan Province. Chin J Schisto Control. 2015;27:116 (in Chinese).

47. Yihuo WL, Zhou YB, Liu GM, Wu ZS, Wang SA, Xu L, Liu HB, Jiang QW. Effect of four-year comprehensive schistosomiasis control in Puge County, Sichuan Province. Chin J Schisto Control. 2009;21:276-9 (in Chinese).

48. Zhang L, Xu ZM, Qian YJ, Dang H, Lu S, Xu J, Li SZ, Zhou XN. Endemic situation of schistosomiasis in People's Republic of China. Chin J Schisto Control. 2016;28:611-7 (in Chinese).

49. Lei ZL, Zhou XN. Eradication of schistosomiasis: a new target and a new task for the National Schistosomiasis Control Porgramme in the People's Republic of China. Chin J Schisto Control. 2015;27:1-4 (in Chinese).

50. Bergquist R, Yang GJ, Knopp S, Utzinger J, Tanner M. Surveillance and response: Tools and approaches for the elimination stage of neglected tropical diseases. Acta Trop. 2015;141:229-34.

51. Zhou XN, Bergquist R, Tanner M. Elimination of tropical disease through surveillance and response. Infect Dis Poverty. 2013;2:1.

52. Tambo E, Ai L, Zhou X, Chen JH, Hu W, Bergquist R, Guo JG, Utzinger J, Tanner M, Zhou XN. Surveillance-response systems: the key to elimination of tropical diseases. Infect Dis Poverty. 2014;3:17.

\section{Submit your next manuscript to BioMed Central and we will help you at every step:}

- We accept pre-submission inquiries

- Our selector tool helps you to find the most relevant journal

- We provide round the clock customer support

- Convenient online submission

- Thorough peer review

- Inclusion in PubMed and all major indexing services

- Maximum visibility for your research

Submit your manuscript at www.biomedcentral.com/submit
Biomed Central 